\title{
Diagnosis of Vascular Prosthesis Infection: PET or SPECT?
}

$\mathbf{T}$ he well-established gold standard for imaging infection is scintigraphy with radiolabeled autologous white blood cells (WBCs). Indeed, 2 years ago, in a metaanalysis of all papers published in the previous 20 years on imaging techniques for the diagnosis of infection (1-4), the importance of WBC scanning in this field clearly emerged, with few exceptions. In particular, for the diagnosis of vascular graft infection, although scintigraphy with WBCs was found to be most accurate, the authors concluded that the new hybrid modalities SPECT/CT and PET/CT would have highly enhanced the use of WBCs and

See page 1230

${ }^{18} \mathrm{~F}-\mathrm{FDG}$, respectively, allowing precise localization of abnormal uptake in the vascular graft. Thus, the possibility of exact anatomic localization of pathologic uptake seems as important as the choice of radiopharmaceutical. However, 2 other important factors remain to be validated when a technique is proposed for in vivo diagnosis of infection: standardization of image acquisition times and standardization of image interpretation criteria, including quantitative and semiquantitative measurements.

During the last few years, ${ }^{18} \mathrm{~F}-\mathrm{FDG}$ PET has been widely used for the

Received Apr. 30, 2007; revision accepted Jun. 8, 2007.

For correspondence or reprints contact: Alberto Signore, MD, PhD, Nuclear Medicine, University "Sapienza," Ospedale S. Andrea, Via di Grottarossa 1035, 00189 Rome, Italy. E-mail: alberto.signore@uniroma1.it COPYRIGHT ( 2007 by the Society of Nuclear Medicine, Inc.

DOI: 10.2967/jnumed.107.042002 diagnosis or follow-up of many inflammatory diseases. Because ${ }^{18} \mathrm{~F}-\mathrm{FDG}$ is not specific for infection but is taken up by inflammatory cells with high glucose metabolism (5), many investigators have suggested the use of ${ }^{18} \mathrm{~F}$-FDG PET for detecting infection and, in particular, for evaluating suspected vascular graft infections (6-16). For example, in a patient with infection after orthopedic surgery, ${ }^{18}$ F-FDG PET also revealed an aortic valve infection (17). Unfortunately, because many of the studies on this topic have been case reports or have included few patients, it is not yet possible to accurately assess the value of ${ }^{18} \mathrm{~F}-\mathrm{FDG}$ PET in the diagnosis of vascular graft infection. Similarly, it is difficult to draw any conclusions about the best image acquisition times, interpretation criteria, and methods of quantitative analysis.

Nevertheless, the data accumulated so far allow us to pose a few considerations.

CT-with its excellent spatial resolution, widespread availability, and high sensitivity - has been the first-line imaging method for assessing graft infection. In infections that are of low grade or in the early stages, the sensitivity of CT decreases because of morphologic changes preventing inflammation from being distinguished from noninflammatory changes, such as those after surgery or due to scarring or therapy $(14,18)$. Today, scintigraphy with autologous WBCs labeled with ${ }^{111} \mathrm{In}$-oxine or ${ }^{99 \mathrm{~m}} \mathrm{Tc}$-hexamethylpropylene amine oxime is the technique of choice for identifying graft infection, because of high sensitivity and specificity $(97.7 \%$ and $88.6 \%$, respectively, for ${ }^{99 \mathrm{~m}} \mathrm{Tc}-\mathrm{WBCs}$ ). Labeled WBCs accumulate at and thus identify sites of infection through diapedesis, chemo- taxis, and vascular permeability. Moreover, the labeling procedures, acquisition modalities, and interpretation methods are well established, guaranteeing that similar results will be obtained in different departments and countries $(1,19)$. The 2 major drawbacks of this method are the need to manipulate blood and the lengthiness of the examination. Of course, ${ }^{18}$ F-FDG PET strongly competes with WBC scintigraphy. Indeed, after intracellular phosphorylation, ${ }^{18} \mathrm{~F}$ FDG is trapped within neutrophils in relation to the respiratory burst; thus, the detection of inflammatory sites is independent of the homing and timing of leukocyte migration. For this reason, ${ }^{18}$ F-FDG PET results may be available within $1 \mathrm{~h}$ of ${ }^{18} \mathrm{~F}-\mathrm{FDG}$ administration as opposed to $24 \mathrm{~h}$ in the case of labeledWBC studies (20). However, the best choice of acquisition time for ${ }^{18} \mathrm{~F}-\mathrm{FDG}$ PET studies still needs further investigation and standardization, and in the case of vascular graft infection, a recent study with ${ }^{99 \mathrm{~m}} \mathrm{Tc}-$ hexamethylpropylene amine oxime-WBC proposed acquisitions only within $2 \mathrm{~h}$ after the injection of the labeled leukocytes (21). For PET studies, some authors have suggested that images be acquired early (30 min after injection) and others have also suggested dual imaging (acquiring the first image within $1 \mathrm{~h}$ and the second image at about $2 \mathrm{~h}$ ) to differentiate between inflammation and tumors or infection. Abnormal uptake of ${ }^{18} \mathrm{~F}-\mathrm{FDG}$ is often found in vasculitis, giant-cell arteritis, Takayasu's arteritis, venous thrombosis, retroperitoneal fibrosis, and aseptic inflammation $(14,20)$. In addition, asymptomatic and elderly patients may present with increased ${ }^{18} \mathrm{~F}-\mathrm{FDG}$ uptake in the lamina muscularis of large vessels or in atherosclerotic plaques 
TABLE 1

Summary of Published Studies Using ${ }^{18}$ F-FDG in Vascular Graft Infection

\begin{tabular}{|c|c|c|c|c|c|c|c|c|c|c|}
\hline Study & Year & $\begin{array}{l}\text { No. of } \\
\text { patients }\end{array}$ & Method* $^{*}$ & $\begin{array}{c}{ }^{18} \mathrm{~F}-\mathrm{FDG} \\
\text { dose }^{\dagger} \\
(\mathrm{MBq})\end{array}$ & $\begin{array}{l}\text { Acquisition time } \\
\text { (minutes after } \\
\text { injection) }\end{array}$ & $\begin{array}{l}\text { Interpretation } \\
\text { criteria§ }^{\S}\end{array}$ & $\begin{array}{l}\text { True- } \\
\text { positive }\end{array}$ & $\begin{array}{c}\text { True- } \\
\text { negative }\end{array}$ & $\begin{array}{l}\text { False- } \\
\text { positive }\end{array}$ & $\begin{array}{c}\text { False- } \\
\text { negative }\end{array}$ \\
\hline Stumpe (7) & 2000 & 7 & PET & $300-400$ & $30-40$ & Qualitative & 2 & 5 & 0 & 0 \\
\hline Krupnick (12) & 2003 & 1 & PET & 187 & 50 & Qualitative & 1 & 0 & 0 & 0 \\
\hline Chacko (8) & 2003 & 3 & PET & $2.55 / \mathrm{kg}$ & 60 & Qualitative & 2 & 1 & 0 & 0 \\
\hline Keidar (11) & 2003 & 1 & $\mathrm{PET} / \mathrm{CT}$ & 370 & 60 & Qualitative & 1 & 0 & 0 & 0 \\
\hline Stádler (14) & 2004 & 1 & $\mathrm{PET} / \mathrm{CT}$ & 375 & 90 & Qualitative & 1 & 0 & 0 & 0 \\
\hline Fukuchi (15) & 2005 & 33 & PET & 185 & 60 & Semiquantitative & 10 & 14 & 8 & 1 \\
\hline Jaruskova (9) & 2006 & 7 & $\mathrm{PET} / \mathrm{CT}$ & $279-717$ & 40-165 (mean, 70) & Qualitative & 6 & 0 & 1 & 0 \\
\hline Tsunekawa (16) & 2007 & 1 & PET & 185 & 60 & Qualitative & 1 & 0 & 0 & 0 \\
\hline Tegler (25) & 2007 & 1 & $\mathrm{PET} / \mathrm{CT}$ & - & - & Qualitative & 1 & 0 & 0 & 0 \\
\hline Keidar (29) & 2007 & 39 & $\mathrm{PET} / \mathrm{CT}$ & $185-370$ & 90 & $\begin{array}{l}\text { Qualitative based on } \\
\text { morphology }\end{array}$ & 14 & 22 & 2 & 1 \\
\hline
\end{tabular}

*Shows morphologic accuracy in detecting site of ${ }^{18}$ F-FDG uptake.

${ }^{\dagger 18} \mathrm{~F}-\mathrm{FDG}$ dose is usually related to image acquisition time.

${ }^{\ddagger}$ Early or delayed imaging may lead to different diagnostic accuracy.

$\S$ Qualitative or quantitative interpretation may also depend on method used.

because of the presence of macrophages (22).

Another important aspect is the time from surgery: In the early phases of healing and, frequently, in the first months after surgery, ${ }^{18} \mathrm{~F}$-FDG may give false-positive results. Other examinations must then be performed within the following days or weeks to prove a local decrease or increase of ${ }^{18} \mathrm{~F}$-FDG uptake. Moreover, about $40 \%$ of infections in graft prostheses appear within 4 mo after surgery (23). If imaging is required early after surgery, WBC scintigraphy would therefore seem to be more accurate than ${ }^{18}$ F-FDG PET (21).

Unfortunately, as far as quantitative measurement of ${ }^{18} \mathrm{~F}$-FDG uptake is concerned, few papers have been published. Some authors have proposed a progressively increasing 5-point scale based on visual analysis of ${ }^{18} \mathrm{~F}-\mathrm{FDG}$ uptake $(7,15)$, but this method appears to be quite observer-dependent. Still, some work should be done in this direction. Certainly, combining CT with ${ }^{18} \mathrm{~F}-\mathrm{FDG}$ PET increases its specificity $(9,11,14,24,25)$. If we compare all published data on the use of ${ }^{18} \mathrm{~F}$ FDG PET in vascular graft infections (Table 1), it emerges that the combined use of PET and CT improves diagnostic accuracy (in particular, reduces the rate of false-positive cases) by allowing image interpretation based on morphologic criteria. A valid alternative to PET/CT may be SPECT/CT with labeled WBCs. The usefulness of this hybrid method has recently been demonstrated for bone and joint infections $(26,27)$, although the literature currently includes only one case report on vascular prosthesis infection (28).

In light of the cumulated evidence, scintigraphy with radiolabeled WBCs should still be considered the gold standard for imaging vascular graft infection-particularly when improved by the use of a SPECT/CT camerabecause of the extensive validation of the radiopharmaceutical, image acquisition modality, and image interpretation criteria (1). PET and PET/CT with ${ }^{18}$ F-FDG may well become a valid substitute for WBC scintigraphy, provided that large clinical trials validate the best acquisition times and the most reliable imaging analysis and interpretation criteria. The paper by Keidar et al. (29) in this issue of The Journal of Nuclear Medicine represents a welldesigned attempt to achieve such standardization, and similar works are encouraged.

Luca Burroni University of Siena Siena, Italy
Calogero D'Alessandria University "Sapienza" Rome Rome, Italy

\author{
Alberto Signore \\ University "Sapienza" Rome \\ Rome, Italy \\ University Medical Center Groningen \\ University of Groningen \\ Groningen, The Netherlands
}

\section{REFERENCES}

1. Annovazzi A, Bagni B, Burroni L, D'Alessandria C, Signore A. Nuclear medicine imaging of inflammatory/infective disorders of the abdomen. Nucl Med Commun. 2005;26:657-664.

2. Capriotti G, Chianelli M, Signore A. Nuclear medicine imaging of diabetic foot infection: results of meta-analysis. Nucl Med Commun. 2006;27: 757-764.

3. Prandini N, Lazzeri E, Rossi B, Erba P, Parisella MG, Signore A. Nuclear medicine imaging of bone infections. Nucl Med Commun. 2006;27: 633-644.

4. Cascini GL, De Palma D, Matteucci F, et al. Fever of unknown origin, infection of subcutaneous devices, brain abscesses and endocarditis. Nucl Med Commun. 2006;27:213-222.

5. Alavi A, Zhuang H. PET imaging in infectious diseases. In: Valk PE, Bailey DL, Towsend DW, Maisey MN, eds. Positron Emission Tomography. London, U.K.: Springer; 2003:727-739.

6. Sugawara Y, Braun DK, Kison PV, Russo JE, Zasadny KR, Wahl RL. Rapid detection of human infections with fluorine-18 fluorodeoxyglucose and positron emission tomography: preliminary results. Eur J Nucl Med. 1998;25:1238-1243.

7. Stumpe KD, Dazzi H, Shaffner A, Von Schulthess GH. Infection imaging using whole-body FDGPET. Eur J Nucl Med. 2000;27:822-832.

8. Chacko TK, Zhuang H, Nakhoda KZ, Moussavian B, Alavi A. Application of fluorodeoxyglucose 
positron emission tomography in the diagnosis of infection. Nucl Med Commun. 2003;24:615-624.

9. Jaruskova M, Belohlavek O. Role of FDG-PET and PET/CT in the diagnosis of prolonged febrile states. Eur J Nucl Med Mol Imaging. 2006;33: 913-918.

10. Zhuang H, Duarte PS, Pourdehnad M, et al. The promising role of ${ }^{18} \mathrm{~F}-\mathrm{FDG}$ PET in detecting infected lower limb prosthesis implants. $\mathrm{J} \mathrm{Nucl}$ Med. 2001;42:44-48.

11. Keidar Z, Engel A, Nitecki S, Bar Shalom R, Hoffman A, Israel O. PET/CT using 2-deoxy$2-\left[{ }^{18} \mathrm{~F}\right]$ fluoro-D-glucose for the evaluation of suspected infected vascular graft. Mol Imaging Biol. 2003;5:23-25.

12. Krupnick AS, Lombardi JV, Engels FH, et al. 18Fluorodeoxyglucose positron emission tomography as a novel imaging tool for the diagnosis of aortoenteric fistula and aortic graft infection: a case report. Vasc Endovascular Surg. 2003;37:363-366.

13. Rohde H, Horstkotte MA, Loeper S, Aberle J, Jenicke L, Lampidis R. Recurrent Listeria monocytogenes aortic graft infection: confirmation of relapse by molecular subtyping. Diagn Microbiol Infect Dis. 2004;48:63-67.

14. Stádler P, Belohlávek O, Spacek M, Michálek P. Diagnosis of vascular prosthesis infection with FDG-PET/CT. $J$ Vasc Surg. 2004;40:1246-1247.

15. Fukuchi K, Ishida Y, Higashi M, et al. Detection of aortic graft infection by fluorodeoxyglucose posi- tron emission tomography: comparison with computed tomographic findings. J Vasc Surg. 2005;42: 919-925.

16. Tsunekawa T, Ogino H, Minatoya K, Matsuda H, Sasaki H, Fukuchi K. Masked prosthetic graft to sigmoid colon fistula diagnosed by 18 -fluorodeoxyglucose positron emission tomography. Eur J Vasc Endovasc Surg. 2007;33:187-189.

17. Belohlavek O, Votrubova J, Skopalova M, Fencl P. The detection of aortic valve infection by FDG$\mathrm{PET} / \mathrm{CT}$ in a patient with infection following total knee replacement [image of the month]. Eur $J$ Nucl Med Mol Imaging. 2005;32:518.

18. Fiorani P, Speziale F, Rizzo L, DeSantis F, Massimi GJ, Taurino M. Detection of aortic graft infection with leukocytes labelled with technetium 99m-hexametazine. J Vasc Surg. 1993;17:87-96.

19. Roca M, Martin-Comin J, Peters M, et al. I.S.O.R.B.E. guidelines: a consensus protocol for white blood cells labelling with Tc-99-HMPAO Eur J Nucl Med. 1998;25:797-799.

20. Zhuang H, Alavi A. 18-fluorodeoxyglucose positron emission tomographic imaging in the detection and monitoring of infection and inflammation. Semin Nucl Med. 2002;32:47-59.

21. Liberatore M, Misuraca M, Calandri E, et al. White blood cell scintigraphy in the diagnosis of infection of endovascular prostheses within the first month after implantation. Med Sci Monit. 2006;12:MT5-MT9.
22. Mochizuki Y, Fujii H, Yasuda S, Nakahara T, Takahashi W, Ide M. FDG accumulation in aortic walls. Clin Nucl Med. 2001;26:68-69.

23. Ducasse E, Calisti A, Speziale F. Aortoiliac stent graft infection: current problems and management. Ann Vasc Surg. 2004;18:521-526.

24. Townsend DW, Carney JP, Yap JT, Hall NC. PET/CT today and tomorrow. J Nucl Med. 2004;45(suppl): S4-S14.

25. Tegler G, Sorensen J, Bjorck M, Savitcheva I, Wanhainen A. Detection of aortic graft infection by 18 -fluorodeoxyglucose positron emission tomography combined with computed tomography. J Vasc Surg. 2007;45:828-830.

26. Filippi L, Schillaci O. Usefulness of hybrid SPECT/CT in 99m-Tc-HMPAO-labeled leukocyte scintigraphy for bone and joint infections. $\mathrm{J} \mathrm{Nucl}$ Med. 2006;47:1908-1913.

27. Horger M, Eschmann SM, Pfannenberg C, et al. The value of SPECT/CT in chronic osteomyelitis. Eur J Nucl Med Mol Imaging. 2003;30:1665-1673.

28. Hofmann A, Zettinig G, Wachter S, Kurtaran A, Kainberger F, Dudczak R. Imaging of aortic prosthesis infection with a combined SPET/CT device. Eur J Nucl Med Mol Imaging. 2002; 29:836.

29. Keidar Z, Engel A, Hoffman A, Israel O, Nitecki S. Prosthetic vascular graft infection: the role of ${ }^{18}$ F-FDG PET/CT. J Nucl Med. 2007;48: 1230-1236. 